\title{
A NECESSÁRIA RELATIVIZAÇÃO DO PRINCÍPIO DA PUBLICIDADE NO PROCESSO ELETRÔNICO EM VIRTUDE DO DIREITO AO ESQUECIMENTO
}

\section{THE NECESSARY RELATIVIZATION OF THE PUBLICITY PRINCIPLE AND THE RIGHT TO BE LEFT ALONE}

\author{
Adriane Guasque $e^{*}$ \\ Barbara Guasque $^{* *}$
}

\begin{abstract}
RESUMO
A hodierna sociedade de informação e os avanços tecnológicos desencadearam a necessária discussão do esquecimento como um direito a ser ampliado para as demais em virtude da facilidade de circulação e de manutenção de informação, dados pessoais e notícias pela internet. No que concerne ao processo eletrônico, se os dados completos de toda a movimentação processual figurasse disponível, ampliaria sensivelmente o acesso irrestrito e eterno aos dados pessoais e processuais, carreando possíveis consequências nefastas a um grande contingente de pessoas. É preciso verificar se uma ampla e irrestrita publicidade de atos e dados processuais, em respeito ao princípio da publicidade, não cede no confronto com a preservação da intimidade e também com esse novo direito que exsurge como corolário da dignidade da pessoa humana e vem se consagrando nos últimos anos - o direito ao esquecimento.
\end{abstract}

Palavras-chave: Princípio da publicidade. Direito ao esquecimento. Processo eletrônico. Direito da personalidade.

\begin{abstract}
Today's information society and technological advances triggered the necessary discussion about forgetting as aright to be extended to everyone because of the ease of spreading and storing information, personal data and new sonthe Internet. Regarding electronic processes, if complete data of all procedural motion were made available, it would broadenun restricted and lifelong access to personal and procedural data causing possible adverse consequences to a large number of people. It is necessary to verify if broad and unrestricted sharing of acts and procedural data, in respect to the principle of publicity, does not frustrate the preservation of intimacy and withth is new law which came as a consequence of human dignity that has been gaining space in recent years - the right to be left alone.
\end{abstract}

Keywords: Publicity principle. Right to be alone. Electronic process. Personality right personality.

"Doutoranda em Ciência Jurídica pela UNIVALI

** Mestre em Ciência Jurídica pela UNIVALI 


\section{Introdução}

O avanço tecnológico trouxe a necessidade de se discutir a relevância da temática do esquecimento como um direito, vez que, ao contrário do que acontece com a memória humana, a internet pereniza os erros passados, as fotos, os vídeos e os acontecimentos os quais se gostaria que fossem esquecidos

O potencial danoso da veiculação de informações da esfera privada e na intimidade, ainda que verídicas, são infinitamente superiores do que na época em que se davam pelos meios tradicionais físicos. A internet não permite o esquecimento. Sem que exista alguma garantia como o direito ao esquecimento, o indivíduo estará fadado e ter seus dados e erros do passado a persegui-lo e prejudicá-lo por toda a vida. Isso certamente fere a intimidade e a dignidade da pessoa humana.

Em que pese ter ficado por tempos restrito à seara penal, a hodierna sociedade de informação e os avanços tecnológicos desencadearam a necessária ampliação para as demais áreas em virtude da facilidade de circulação e de manutenção de informação, dados pessoais e notícias pela internet.

Atualmente a jurisprudência nacional e internacional tem reconhecido e consagrado o direito ao esquecimento.

No que concerne aos dados de processos judiciais os prejuízos advindo serão certamente mais drásticos. Em virtude deste fato é que a maioria dos países europeus adota o anonimato nos bancos de dados jurisprudências disponíveis na internet. Também em virtude destes fatos é que o objetivo do presente estudo é demonstrar a necessária relativização do princípio da publicidade no processo judicial eletrônico brasileiro.

Para tanto, na fase de investigação, utilizarse-á o método indutivo. O método procedimental será o monográfico e a técnica de pesquisa utilizada será a bibliográfica e exploratória, a fim de analisar as recentes decisões acerca do tema.

\section{1 - O princípio da publicidade}

O princípio da publicidade tem por cerne garantir a imparcialidade e transparência das atividades jurisdicionais; caracterizando-se como uma salutar ferramenta fiscalizatória, permitindo que, não somente as partes, mas toda a sociedade tenha acesso às decisões judiciais permitindo o acesso dos cidadãos às audiências. Em se tratando da nossa mais alta Corte de Justiça, a publicidade é ainda mais ampla, vez que os julgamentos são transmitidos ao vivo através da TV Justiça.

$\mathrm{Na}$ prestação jurisdicional há um interesse maior do que o interesse privado defendido pelas partes: é a garantia da paz e harmonia social, procurada através da manutenção da ordem social.

Por esta razão, a justiça não pode ser secreta, de modo que todos, e não somente as partes, têm o direito de conhecer e acompanhar tudo o que se passa durante o processo. Todos têm o direito de acesso aos atos do processo, exatamente como meio de se dar transparência à atividade jurisdicional.

A publicidade dos atos processuais é uma garantia processual dada pela Constituição no art. $5 .^{\circ}$, LX: "LX - a lei só poderá restringir a publicidade dos atos processuais quando a defesa da intimidade ou o interesse social o exigirem".

Após a emenda constitucional 45, foi inserido o inciso IX ao art. 93, garantindo a publicidade no julgamento de todos os órgãos do Poder Judiciário, com a seguinte redação:

IX todos os julgamentos dos órgãos do Poder Judiciário serão públicos, e fundamentadas todas as decisões, sob pena de nulidade, podendo a lei limitar a presença, em determinados atos, às próprias partes e a seus advogados, ou somente a estes, em casos nos quais a preservação do direito à intimidade do interessado no sigilo não prejudique o interesse público à informação.

O que antes se tratava de uma garantia processual passou a ser constitucional, estabelecendo uma preciosa garantia ao indivíduo no tocante ao exercício da jurisdição, uma vez que a presença de público nas audiências e a possibilidade do exame de autos por qualquer pessoa configuram o mais popular e democrático instrumento de fiscalização popular sobre a obra dos magistrados, promotores e advogados.

Arruda Alvim leciona que a "publicidade é garantia para o povo de uma justiça justa, que nada tem a esconder; e, por outro lado, é também garantia para a própria Magistratura diante do povo, pois agindo publicamente, permite a verificação de seus atos".

Além do objetivo da publicidade geral (extra partes), há que se observar outra faceta sua, que é 
a de levar ao conhecimento das partes o conteúdo das decisões proferidas no Processo, para que tomes as providências que lhe dizem respeito, bem como, para que tenham conhecimento das manifestações da parte adversa. Eventual determinação de que alguma providência seja tomada pela parte somente se torna exigível a partir do seu conhecimento pela destinatária.

Este princípio, porém, não impede que existam processos que correm em segredo de justiça, no interesse das próprias partes (art. 155 do CPC). Este sigilo excepcional não é absoluto, visto que as partes e seus advogados terão sempre garantido o acesso a todos os atos praticados no processo. Deste modo, o sigilo é restrito aos estranhos à relação jurídica processual.

\section{2 - O Direito ao esquecimento}

O direito ao esquecimento, como o próprio nome sugere, é o direito de que fatos passados não mais sejam expostos publicamente ante a passagem de um determinado período de tempo.

Tratado no direito norte-americano como "the right to be alone", garante que os dados sobre uma pessoa somente serão conservados de maneira a permitir a identificação do sujeito a eles ligado, além de somente poder ser mantido durante o tempo necessário para suas finalidades. ${ }^{1}$

$\mathrm{O}$ avanço tecnológico trouxe a necessidade de se discutir a relevância da temática do esquecimento como um direito vez que "os limites da memória humana contrastam com a infalibilidade da memória na internet" ${ }^{\text {" }}$ que pereniza os erros passados, as fotos, os vídeos e os acontecimentos os quais gostaríamos de esquecer.

O potencial danoso da veiculação de informações da esfera privada e na intimidade, ainda que verídicas, são infinitamente superiores do que na época em que se davam pelos meios tradicionais físicos. A internet não permite o esquecimento jamais. Sem

\footnotetext{
${ }^{1}$ RULLI JÚNIOR, A.; RULLI NETO, A. O direito ao esquecimento e o superinformacionismo: apontamentos no direito brasileiro dentro do contexto de sociedade da informação. Revista do Instituto do Direito Brasileiro, ano 1, n 1, p. 419-434, 2012.

2 TERWANGNE, CÉCILE. Privacidaden internet y elderecho a ser olvidado/ derecho al olvido. Revista de Internet Derecho y Política. Disponível em: $<$ http://www.redalyc.org/pdf/788/78824460006.pdf> acesso em 01. dez. 2014 .
}

que exista alguma garantia como o direito ao esquecimento, o indivíduo estará fadado e ter seus dados e erros do passado a persegui-lo e prejudicá-lo por toda a vida. Isso certamente fere a intimidade e a dignidade da pessoa humana.

A faceta mais evidente do direito ao esquecimento é no que concerne aos antecedentes criminais do indivíduo. O reconhecimento de dito direito é corolário de uma intenção de ressocialização do indivíduo o qual, uma vez que cumpriu sua pena ou quitou seu débito com a justiça, não precisa suportar os erros de seu passado pelo resto da sua vida.

Pode-se afirmar que o direito ao esquecimento já se vislumbrava na legislação penal brasileira, conforme se extrai do art. 93 do Código Penal, que estipula que a reabilitação alcança quaisquer penas aplicadas em sentença definitiva, sendo assegurado ao condenado o sigilo dos registros de seu processo e condenação. Assim como no art. 748 do Código de Processo Penal, que garante que não serão mencionados na folha de antecedentes criminais do reabilitado, as condenações anteriores, salvo quando requisitada por juiz criminal. Da mesma forma, o art. 202 da Lei de Execuções Penais, exalta que após o cumprimento ou extinção da pena, não constarão da folha corrida, atestados ou certidões fornecidas por autoridade policial ou por auxiliares da justiça, qualquer notícia ou referência à condenação, salvo para instruir processo pela prática de nova infração penal ou outros casos expressos em lei. ${ }^{3}$ Também o Código de Defesa do Consumidor contemplou a necessidade do esquecimento em seu artigo $43, \S 1^{\circ}$, que estabelece o prazo máximo de cinco anos para que os inadimplentes permaneçam nos cadastros restritivos de crédito.

Em que pese ter ficado por tempos restrito à seara penal, a hodierna sociedade de informação e os avanços tecnológicos desencadearam a necessária ampliação para as demais áreas em virtude dafacilidade de circulação e de manutenção de informação, dados pessoais enotícias pela internet, capaz de proporcionar o que se denomina superinformacionismo, "uma verdadeira massa de informações sobre tudo e sobre

\footnotetext{
${ }^{3}$ BORSSATI, SUELEN; HOFFMAN, JORGE EDUARDO. Direito ao esquecimento: conflito entre os direitos da personalidade e a liberdade de imprensa. In: Diálogos sobre Direito e Justiça. Joaçaba/SC: Editora Unoesc, 2014, p. 195. ebook<http://www.unoesc.edu.br/images/uploads/atendimento/E-book_Dialogo_Sobre_Direito_e_Justi\%C3\%A7a.pdf>
} 
todos, queiram ou não estar naqueles conjuntos de dados ou informações" ${ }^{\text {. }}$. Esta superexposição de fatos e notícias a qualquer momento ainda possuem como característica a perenização das mesmas nos espaços virtuais, não sofrendo, portanto, a ação do tempo atuante em todos os meios físicos de divulgação de dados.

No entanto, o marco de sua expansão e aplicação nas demais áreas foi a aprovação do Enunciado 531 na VI Jornada de Direito Civil que dispôs: "A tutela da dignidade da pessoa humana na sociedade da informação inclui o direito ao esquecimento", incluindo o direito ao esquecimento entre os direitos da personalidade.

O desembargador do Tribunal Regional Federal da $5^{\text {a }}$ Região Rogério Fialho Moreira, que coordenou a Comissão de Trabalho da Parte Geral na VI Jornada salienta que se na esfera criminal, quando extinta a punibilidade, a certidão criminal solicitada sai negativa, inclusive sem qualquer referência ao crime ou ao cumprimento de pena, sendo, portanto, concedido o direito ao esquecimento, "não parece justo que os atos da vida privada, uma vez divulgados, possam permanecer indefinidamente nos meios de informação virtuais". 5

Por certo que não se trata de um direito absoluto, nem que se sobreponha ao direito à liberdade de informação e de manifestação de pensamento. Conforme alude o promotor de Justiça do Rio de Janeiro Guilherme Magalhães Martins, autor do enunciado 531: "É necessário que haja uma grave ofensa à dignidade da pessoa humana, que a pessoa seja exposta de maneira ofensiva. Porque existem publicações que obtêm lucro em função da tragédia alheia, da desgraça alheia ou da exposição alheia. E existe sempre um limite que deve ser observado"6.

Atualmente a jurisprudência tem reconhecido o direito ao esquecimento com base no direito a intimidade ou como parte dos direitos da personalidade.

\footnotetext{
${ }^{4}$ RULLI JÚNIOR, A.; RULLI NETO, A. O direito ao esquecimento e o superinformacionismo: apontamentos no direito brasileiro dentro do contexto de sociedade da informação. Revista do Instituto do Direito Brasileiro, ano 1, n 1, p. 419-434, 2012.

${ }^{5}$ Direito ao esquecimento é garantido por Turma do STJ. Revista Consultor Jurídico, 21 de outubro de 2013. Disponível em: http://www.conjur.com. br/2013-out-21/direito-esquecimento-garantido-turma-stj-enunciado-cjf $>$ acesso em 02. Dez. 2014.

${ }^{6}$ Direito ao esquecimento é garantido por Turma do STJ. Revista Consultor Jurídico, 21 de outubro de 2013. Disponível em: http://www.conjur.com. br/2013-out-21/direito-esquecimento-garantido-turma-stj-enunciado-cjf> acesso em 02. Dez. 2014.
}

Em 2013, a $4^{\mathrm{a}}$ turma do Superior Tribunal de Justiça reconheceu que ninguém é obrigado a conviver para sempre com erros do passado. O caso (REsp 1.334.097), referia-se a um cidadão que foi acusado de coautoria e, posteriormente, inocentado no caso que ficou conhecido como a "Chacina da Candelária". Treze anos após o evento o mesmo foi retratado em um programa de televisão mencionando o envolvimento do autor, o que motivou o autor a buscar a justiça para ter reconhecido o seu direito ao esquecimento. $\mathrm{O}$ autor alegou que negou o pedido de entrevista feita pela emissora de televisão, mas que assim mesmo teve seu nome veiculado como um dos envolvidos no caso da chacina e que mesmo com a absolvição noticiada, o fato reascendeu a ira da comunidade onde residia, compelindo-o a deixar a comunidade aonde vivia a fim de preservar sua própria segurança e de seus familiares. O pedido foi julgado procedente pela $4^{\text {a }}$ Turma do STJ e a emissora de televisão condenada ao pagamento de indenização no montante de R\$50 mil.

Em maio de 2014, decisão proferida pelo Tribunal de Justiça da União Europeia, consagrou o direito ao esquecimento, reconhecendo-o expressamente. $\mathrm{O}$ caso tinha como autor um cidadão espanhol que teve seu nome veiculado no periódico La Vanguardia, nos idos de 1998, em um leilão de imóveis para o pagamento de dívidas à Segurança Social cujo cidadão figurava como um dos devedores.O autor obteve decisão favorável para que fosse removido, dos resultados de pesquisa do Google, a informação que fazia referência de seu nome ao leilão ocorrido à época. Referida decisão acolheu a alegação de que tal fato violava o direito à privacidade do autor. No entanto, a decisão não se estendeu ao meio de comunicação que veiculou o referido leilão com o nome do autor. Isto porque o tribunal considerou o Google responsável pelos links que exibe nos resultados das buscas vez que efetua o que se denomina "tratamento das informações". Portanto, por mais que o site que publicou a notícia não a apague, é possível que a página não mais apareça nos resultados das buscas no Google. ${ }^{7}$

Através desta perfunctória narrativa é possível se vislumbrar a ascensão do direito ao esquecimento

\footnotetext{
Disponível em: <http://www.publico.pt/mundo/noticia/tribunal-europeu-defende-direito-a-ser-esquecido-na-internet-1635712> acesso em 20.dez.2014.
} 
com o reconhecimento de um direito da personalidade necessário à preservação da privacidade e da dignidade da pessoa de modo que dados e acontecimentos, ainda que verídicos, noticiados pela imprensa, não se perenizem, permitindo a reinserção social do indivíduo atingido. Note-se que mesmo uma notícia verídica pode ser objeto de dito direito ao esquecimento, basta, para tal, que referida notícia viole a privacidade e a dignidade, ressalvadas as exceções, como quando se tratar de fatos de interesse histórico ou que sejam relacionados a uma figura pública ou/e no exercício de função pública.

A polêmica envolvendo o direito ao esquecimento, circunscrita hodiernamente, na divulgação de dados na internet bem como a divulgação de notícias em periódicos na web já se revela desafiadora ante as dificuldades em se colocar o direito ao esquecimento em prática. Como é um direito incipiente e que fatalmente entra em conflito com outros princípios e liberdades igualmente legítimos, como a liberdade de expressão e de imprensa, é de rigor que seja analisado o caso concreto e feita uma ponderação entre os direitos abrangidos a fim de se aferir qual deles merece maior proteção no caso em apreço. Caso prevaleça o direito ao esquecimento com fulcro na intimidade e nos direitos da personalidade, a trilha a ser seguida é ainda mais penosa. Necessário se faz a retirada da página com a notícia por parte do periódico que a divulgou; que as informações também sejam excluídas dos motores de busca na internet e, se algum interessado na informação tiver armazenado dita informação, é possível que ela seja reinserida e seja novamente divulgada.

É o caso de um estudante de doutorado em química da Universidade Federal do Rio de Janeiro, ${ }^{8}$ ocorrido em meados de 2005, em que referido estudante foi indiciado por crime de interceptação de dados telemáticos e a matéria foi veiculada apenas em dois jornais que possuem sítios na internet. Jamais houve o aforamento do inquérito policial por falta de provas, no entanto, em simples busca na internet pelo nome do indiciado, que antes contava com seus artigos, hoje há inúmeras páginas afirmando que o mesmo é um criminoso virtual. Aprofundando-se no caso em apreço, descobriu-se que o indiciado foi compelido a buscar

\footnotetext{
${ }^{8}$ ALMEIDA JÚNIOR, José Carlos de Araújo. Processo eletrônico e teoria geral do processo eletrônico: a informatização judicial no Brasil. 3.ed. Rio de Janeiro: Forense, 2010. p.88.
}

a tutela jurisdicional a fim de obrigar que as empresas Google e Yahoo retirassem seu nome de suas buscas robóticas. A decisão foi procedente ao indiciado, contudo, até na presente data, quase dez anos após o ocorrido, ainda foi possível localizar as notícias aliando o nome do indiciado à fraude.

A potência dos motores de busca na internet para coletar dados relativos a um indivíduo, em qualquer momento, desde qualquer lugar, sem nenhum tipo de procedimento administrativo, sem necessidade de se identificar o autor das buscas e de forma gratuita, apresenta um atentado de drásticas consequências à intimidade e à dignidade da pessoa humana. No que concerne aos dados de processos judiciais os prejuízos advindo serão certamente mais drásticos. Em virtude deste fato é que a maioria dos países europeus adota o anonimato nos bancos de dados jurisprudências disponíveis na internet. Também em virtude destes fatos é que se defende a necessária relativização do princípio da publicidade no processo judicial eletrônico brasileiro.

\section{A necessária relativização do princípio da publicidade no processo eletrônico em virtude do direito ao esquecimento}

O princípio da publicidade não é observado em sua totalidade nos processos eletrônicos; isto ocorre porque, muito embora a publicidade dos atos processuais seja uma garantia prevista na Constituição Federal, é preciso resguardar outras garantias igualmente constitucionais como a da intimidade, da dignidade e da própria personalidade das pessoas envolvidas no processo.

Pode-se afirmar que o processo Judicial eletrônico, da forma como se apresenta, atende ao princípio da publicidade, eis que promove a ampliação do conhecimento das etapas processuais, propiciando aos litigantes e à coletividade tomar ciência das decisões nele proferidas, todavia, não de forma absoluta vez que, em determinados casos, duas forças entram em rota de colisão: a publicidade dos atosprocessuais e o direito à intimidade.

Diante desta constatação é que José Carlos de Araújo Almeida Filho defende a necessidade de relativização do princípio da publicidade no âmbito do processo eletrônico. O autor argumenta que a despeito da importância do princípio da publicidade, este cede 
se em confronto com o princípio da dignidade da pessoa humana, sustentáculo da ordem constitucional de 1988. Para ele, é mister repensar a forma de aplicação da publicidade na hodierna sociedade de informação aonde questões como a intimidade e a privacidade não podem estar expostas a uma simples busca na internet. É errônea a constatação de que ante a virtualização do processo, todos os atos processuais devem ser públicos, em obediência à Constituição Federal. Esta excessiva e desnecessária exposição virtual pode acarretar prejuízos à dignidade do ser humano - valor supremo garantido constitucionalmente, e hierarquicamente superior à garantia da publicidade.

Não se quer olvidar a importância do princípio da publicidade, entretanto, mais do que garantir a transparência nos atos judiciais, é preciso preservar a intimidade e a vida privada, direitos da personalidade do ser humano. A própria constituição garante a limitação da publicidade quando da defesa da privacidade, demonstrando, portanto, a valoração que se atribui aos direitos de personalidade.

Os direitos da personalidade são aqueles que "têm por objeto os atributos físicos e morais da pessoa em si e em suas projeções sociais", dentre os quais se inclui o direito à privacidade, também considerada inviolável pelo inciso $\mathrm{X}$ do art. $5 .^{\circ}$ da Constituição Federal. A vida privada é entendida como a vida particular da pessoa natural, compreendendo como uma de suas manifestações o direito à intimidade. ${ }^{9} \mathrm{~A}$ dogmática dos direitos da personalidade surgiu como corolário da noção de respeito à dignidade da pessoa humana, consagrada no art. 1. ${ }^{\circ}$, III, da Constituição Federal.

Vale registrar que a Convenção Interamericana de Direitos Humanos (Pacto de São José da Costa Rica), inserida em nosso ordenamento jurídico positivo pelo Decreto n. ${ }^{\circ} 678$, de 6 de novembro de 1992, determina, no plano internacional, que os Estados se comprometam a respeitar e garantir os direitos da personalidade.

Maria Helena Diniz ${ }^{10}$ reconhece nos direitos da personalidade dupla dimensão: a axiológica, pela qual se materializam os valores fundamentais da pessoa, individual ou socialmente considerada; e a

\footnotetext{
${ }^{9}$ GAGLIANO, Pablo Stolze. Novo curso de direito civil, volumeI: parte geral. 8.ed. São Paulo: Saraiva, 2006. p.171.

${ }^{10}$ DINIZ, Maria Helena. Curso de direito civil brasileiro, volume 1: teoria geral do direito civil. 26.ed. São Paulo: Saraiva, 2009. p.119.
}

objetiva, pela qual consistem em direitos assegurados legal e constitucionalmente, vindo a restringir a atividade dos três poderes, que deverão protegê-los contra quaisquer abusos, solucionando problemas graves que possam advir com o progresso tecnológico, por exemplo, conciliando a liberdade individual com a social.

Exatamente este progresso tecnológico à que alude Maria Helena Diniz e, nomeadamente, o processo eletrônico, que têm o condão de trazer inúmeros prejuízos aos direitos da personalidade (leia-se, direito à intimidade e à vida privada). Almeida Filho ${ }^{11}$ manifesta preocupação diante da possibilidade que as pessoas têm, nos dias de hoje, de consultarem a Internet e, com isto, vasculharem a vida íntima do cidadão. Se uma destas pessoas solicitar emprego em uma empresa, poderá o empregador fazer uma busca na Internet, por exemplo, e identificar se ele possui ações cíveis, como uma execução, de Direito de Família, etc. Sendo o direito de ação garantido a todos, pode até mesmo ocorrer a possibilidade de ajuizamento de demanda totalmente inapropriada que, ainda que no futuro seja julgado improcedente, a parte em questão já se encontra em prejuízo moral e material, porque não obteve o emprego almejado ou mesmo uma promoção.

Uma vez que o art. 20 do Código de Processo Penal prevê que a autoridade assegurará no inquérito o sigilo necessário à elucidação do fato ou exigido pelo interesse da sociedade, a inserção de todos os atos processuais na internet, via processo eletrônico, é uma afronta ao texto legal que pode causar sérios prejuízos à honra e à dignidade da pessoa humana.

O mau uso da publicidade pode ocasionar uma mancha indelével na vida de um cidadão, com o agravante de ser na rede mundial de computadores, vez que na mídia convencional as informações são paulatinamente esquecidas, enquanto que a internet não permite o esquecimento. As pessoas que têm seus nomes e imagens publicados nos sistemas de divulgação de dados Google, Yahoo, Youtube ou em redes sociais, deles não conseguem livrar-se jamais, pouco importando se a informação é certa ou errada, nova ou antiga, boa ou má. A internet retira do cidadão o direito ao esquecimento que garante que os dados sobre uma pessoa somente serão conservados

\footnotetext{
${ }^{11}$ ALMEIDA FILHO, José Carlos de Araújo. Processo eletrônico e teoria geral do processo eletrônico: a informatização judicial no Brasil. 3.ed. Rio de Janeiro: Forense, 2010. p.92.
} 
de maneira a permitir a identificação do sujeito a eles ligado, além de somente poder ser mantido durante o tempo necessário para suas finalidades.

O desembargador federal aposentado do TRF 4. ${ }^{a}$ Região, Vladimir Passos de Freitas, cita o professor Ángel Acedo Penco, da Universidade de Extremadura,Ceddal - Espanha; chamando a atenção para o fato de que, mesmo nos casos de delitos graves com sentença condenatória, as pessoas têm o direito de livrar-se dos efeitos da pena, seja por cumpri-la, seja pela existência da prescrição. Como é possível que possam ficar tão desprotegidos os cidadãos por fatos de sua vida privada, muitas vezes publicados na mídia, verdadeiros ou não? ${ }^{12}$ Tomemos por exemplo um caso de estupro. Como ficará a vítima com o fato e todos os detalhes dos autos expostos na no processo eletrônico via internet? E em caso de uma demissão por justa causa? Provavelmente este trabalhador estaria relegado ao ostracismo, vez que dificilmente teria outra oportunidade de trabalho.

A veiculação de dados processuais, nomeadamente da seara criminal, na rede mundial de computadores, caracteriza uma pena perpétua ao acusado. E pior, uma pena perpétua que passa da pessoa do acusado, afinal a perpetuação da disponibilidade de dados processuais certamente afetará também seus filhos, sua família; revogando, desta forma, o princípio de que a pena não passará da pessoa do condenado.

As notícias judiciais, com o advento da Internet, não permitem o esquecimento, tornando a notícia imperecível e acarretando inúmeros prejuízos como os já narrados alhures e que foram objeto de indenização nas recentes decisões tomadas pelas nossas Cortes. Com a ampla e irrestrita disponibilização de dados processuais no processo eletrônico, milhões de processos, pessoas e lides estariam expostos, acarretando imensuráveis prejuízos a um indeterminado número de pessoas.

Um grupo de trabalhos do Conselho Nacional de Justiça se reuniu para discutir o texto da resolução que irá regulamentara publicidade dos atos processuais eletrônicos na internet. Cerca de 70 propostas foram encaminhadas ao Conselho, por

\footnotetext{
${ }^{12}$ FREITAS, Vladimir Passos. Internet, direito ao esquecimento $\mathbf{x}$ pena perpétua. Disponível em: <http://www.conjur.com.br/2011-nov-06/segunda-leitura-internet-direito-esquecimento-pena-perpetua>. Acesso em: 04 fev. 2013.
}

meio de uma consulta pública. Entre as manifestações recebidas pelo $\mathrm{CNJ}$ na consulta pública está a de um cidadão que conta ter sido condenado em 2002 a dois anos e quatro meses de pena em regime aberto e que até hoje sofre efeitos da condenação, por causa da divulgação de dados relativos ao seu processo. Outra pessoa alertou que existem empresas que exploram comercialmente o fornecimento de informações processuais privilegiadas. De acordo com Walter Nunes, o objetivo da resolução é exatamente combater esses tipos de práticas, evitando efeitos negativos que essa publicidade pode gerar a pessoas envolvidas em processos ou que já foram absolvidas pela Justiça. ${ }^{13}$

No processo eletrônico, ante a inexistência de uma norma regulamentadora que garanta a efetiva proteção de dados, a ideia de relativização do princípio da publicidade pode ser bem aplicada. Segundo Almeida Filho, "vigorando o Processo Eletrônico, entendemos que o princípio da publicidade deve ser repensado, porque o direito ao esquecimento, como uma das garantias ao direito da personalidade, não estará a salvo."14

Para tanto, a adoção de critérios de ponderação de princípios se mostra como a alternativa mais segura para conciliar a dicotomia entre publicidade e intimidade. Conforme leciona Guilherme Marinoni: ${ }^{15}$

quando há colisão de princípios, um deve ceder diante do outro, conforme as circunstâncias do caso concreto. De modo que não há como se declarar a invalidade do princípio de menor peso, uma vez que ele prossegue íntegro e válido no ordenamento, podendo merecer prevalência, em face do mesmo princípio que o precedeu, diante de outra situação concreta.

Levando-se a cabo o princípio da publicidade irrestrita, seria possível que, ressalvados os casos de segredo de justiça, após o trânsito em julgado e cumprimento da sentença um indivíduo poderia lançar todo o processado na Internet, vez que as bases de dados do Tribunal admitem o acesso irrestrito, garantido pela Constituição, a qualquer cidadão.

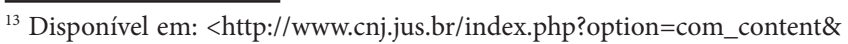
view=article\&id=9338\&Ite mid=675>. Acesso em: 05 fev. 2013.

${ }^{14}$ ALMEIDA JÚNIOR, José Carlos de Araújo. Processo eletrônico e teoria geral do processo eletrônico: a informatização judicial no Brasil. 3.ed. Rio de Janeiro: Forense, 2010. p.84.

${ }^{15}$ MARINONI, Luiz Guilherme. Teoria geral do processo. Curso de Processo Civil. Vol. I. 3.ed. São Paulo: Revista dos Tribunais, 2008. p.55.
} 
Também é verdade que a virtualização do processo não se preocupa, como deveria, com o respeito ao tratamento de dados pessoais.

Em artigo denominado "A informatização do processo”, Almir Pazzianotto Pinto, ex- presidente do Tribunal Superior do Trabalho, comunga com este posicionamento ao afirmar que:

Salvo excepcionais casos em que deve prevalecer o segredo de justiça, a ação judicial é de natureza pública. Não significa, contudo, que deve ser exposta ao conhecimento de quem nela não tem interesse. $\mathrm{O}$ TST, aliás, veda a divulgação dos nomes de reclamantes, receando causar-lhes dificuldades de obtenção de novo emprego. ${ }^{16}$

Infere-se do exposto que, inexistindo a proteção de dados telemáticos no processo eletrônico a relativização do princípio da publicidade, notadamente diante do reconhecimento do direito ao esquecimento como um direito da personalidade; se mostra como única alternativa apta a impedir possíveis violações ao direito fundamental à intimidade, à vida privada e à dignidade da pessoa humana.

Criaremos maiores problemas, no já tão debilitado sistema processual brasileiro, se este novo processo não puder assegurar a segurança e o manuseio adequado dos dados, a fim de não expor a vida dos cidadãos litigantes.

Nas palavras de Almeida Filho:

o Processo moderno não deve se intimidar diante das novas tecnologias, ao mesmo passo em que as novas tecnologias não podem suplantar princípios seculares consagrados. Desde a Proclamação da Revolução Francesa e seguindo a linha histórica, com a Declaração dos Direitos do Homem, o direito da personalidade sempre foi - e deverá continuar sendo - um princípio sagrado, que poderá sobrepor-se a outros de inferioridade hierárquica no sistema constitucional pátrio. ${ }^{17}$

O presente estudo não colacionou exemplos de casos com consequências negativas no processo eletrônico, limitando-se a teorização acerca dos malefícios que certamente adviriam da publicidade

\footnotetext{
16 PINTO, Almir Pazzianotto. A informatização do processo. Disponível em: <http://www. migalhas.com.br/dePeso/16,MI147975,31047-A+informatizacao+do+processo >. Acesso em: 06 fev. 2013.

${ }^{17}$ ALMEIDA JÚNIOR, José Carlos de Araújo. Processo eletrônico e teoria geral do processo eletrônico: a informatização judicial no Brasil. 3.ed. Rio de Janeiro: Forense, 2010. p.94.
}

irrestrita neste meio, em virtude de que, da maneira com quem foi implementado, referido processo já adota a necessária (e aqui defendida) relativização da publicidade. Isto deve-se, justamente, ante a ausência de efetiva norma que regulamente e garanta a proteção dos dados. De modo que, o objetivo do estudo efetuado, foi de ratificar uma prática já adotada e primar pela sua continuidade em defesa de valores supremos como a intimidade e a dignidade da pessoa humana.

\section{Considerações Finais}

Em que pese ter ficado por tempos restrito à seara penal, a hodierna sociedade de informação e os avanços tecnológicos desencadearam a necessária ampliação do direito ao esquecimento para as demais áreas em virtude da facilidade de circulação e de manutenção de informação, dados pessoais e notícias pela internet. As recentes decisões nacionais e internacionais reconhecem e consagram referido direito como um direito da personalidade necessário à preservação da privacidade e da dignidade da pessoa de modo que dados e acontecimentos, ainda que verídicos, noticiados pela imprensa, não se perenizem, permitindo a reinserção social do indivíduo atingido.

Trazendo à calva casos empíricos de consideráveis prejuízos oriundos da divulgação de notícias judicias, casos que obtiveram o direito ao esquecimento reconhecido judicialmente; procurou-se demonstrar que a sistemática adotada pelo processo eletrônico, em que o princípio da publicidade é relativizado e os dados processuais não são divulgados de maneira pública e irrestrita, deve ser mantida. Restou latente que o mau uso da publicidade pode ocasionar uma mancha indelével na vida de um cidadão. E, se notícias veiculadas já possuem o condão de acarretar tamanhas consequências, a disponibilidade ampla e irrestrita de toda a movimentação processual certamente angaria consequências ainda mais nefastas a um enorme contingente de pessoas, desrespeitando o direito ao esquecimento, e, consequentemente, a intimidade e a dignidade.

Se acaso existisse ampla e irrestrita publicização no processo eletrônico, os dados completos de toda a movimentação processual ficariam disponíveis, ampliando sensivelmente este acesso irrestrito e eterno aos dados. Processos 
criminais, cíveis, trabalhista, tudo estaria disponível a uma simples consulta, com prejuízos imensuráveis.

Uma vez que não inexiste, no processo eletrônico, norma que regulamente e garanta a efetiva proteção de dados, a ideia de mitigação da publicidade é de rigor, nomeadamente em virtude deste novo direito da personalidade recentemente reconhecido - o direito ao esquecimento, um corolário do direito fundamental à intimidade, à vida privada e à dignidade da pessoa humana - valores supremos constitucionalmente protegidos.

\section{Referências}

ALMEIDA JÚNIOR, José Carlos de Araújo. Processo eletrônico e teoria geral do processo eletrônico: a informatização judicial no Brasil. 3.ed. Rio de Janeiro: Forense, 2010.

ALMEIDA JÚNIOR, José Carlos de Araújo. A segurança de informação no processo eletrônico e a necessidade de regulamentação da privacidade de dados. Disponível em: $<$ http://www.dgaf.com. br/index_arquivos/ASEGURAN\%C3\% 87ADAINFORMA $\% \mathrm{C} 3 \% 87 \% \mathrm{C} 3 \% 83$ ONOPROCESSOELE TR\%C3\%94NICO.pdf $>$. Acesso em: 05 fev. 2013.

BORSSATI, SUELEN; HOFFMAN, JORGE EDUARDO. Direito ao esquecimento: conflito entre os direitos da personalidade e a liberdade de imprensa. In: Diálogos sobre Direito e Justiça. Joaçaba/SC: Editora Unoesc, 2014, p. 195. ebook<http://www.unoesc.edu.br/images/ uploads/atendimento/E-book_Dialogo_Sobre_Direito_e Justi\%C3\%A7a.pdf>

DINIZ, Maria Helena. Curso de direito civil brasileiro, volume 1: teoria geral do direito civil. 26.ed. São Paulo: Saraiva, 2009.

FREITAS, Vladimir Passos. Internet, direito ao esquecimento $\mathbf{x}$ pena perpétua. Disponível em: $<\mathrm{http} / / /$ www.conjur.com.br/2011-nov-06/segunda-leitura-internetdireito-esquecimento-pena-perpetua>. Acesso em: $04 \mathrm{fev}$. 2013.

GAGLianO, Pablo Stolze. Novo curso de direito civil, volumeI: parte geral. 8.ed. São Paulo: Saraiva, 2006.

MARINONI, Luiz Guilherme. Teoria geral do processo. Curso de Processo Civil. Vol. I. 3.ed. São Paulo: Revista dos Tribunais, 2008.

PINTO, Almir Pazzianotto. A informatização do processo. Disponível em: $<\mathrm{http} / / / \mathrm{www}$. migalhas.com.br/dePeso/16, MI147975,31047A+informatizacao+do+processo>. Acesso em: 06 fev. 2013.

RULli JÚNIOR, A.; RULLI NETO, A. O direito ao esquecimento e o superinformacionismo: apontamentos no direito brasileiro dentro do contexto de sociedade da informação. Revista do Instituto do Direito Brasileiro, ano 1, n 1, p. 419-434, 2012.

TERWANGNE, CÉCILE. Privacidaden internet y elderecho a ser olvidado/derecho al olvido. Revista de Internet Derecho y Política. Disponível em: <http://www.redalyc. org/pdf/788/78824460006.pdf> acesso em 01. dez. 2014.

Notícias extraídas da worldwide web (www)

http://www.conjur.com.br/2013-out-21/direitoesquecimento-garantido-turma-stj-enunciado-cjf

http://www.cnj.jus.br/index.php?option=com_content\&vie $\mathrm{w}=$ article $\& \mathrm{id}=9338 \&$ Ite $\mathrm{mid}=675$

http://www.publico.pt/mundo/noticia/tribunal-europeudefende-direito-a-ser-esquecido-na-internet-1635712

Recebido em: 15/01/2015

Aceito em: 12/03/2015 